\title{
Tratamentos químicos aplicados a capim elefante visando à produção de bioetanol
}

\author{
Samantha Freire Mendes (IC), Camila Alves de Rezende (PQ), Instituto de Química - IQ, UNICAMP \\ Resumo \\ A utilização de fontes de energia limpas e renováveis é uma alternativa promissora para o atual \\ cenário de produção e consumo energético. Neste projeto, foram realizados tratamentos \\ termoquímicos com ácidos e bases em diferentes concentrações em amostras de capim elefante, \\ com o objetivo de aumentar o teor de celulose nessas amostras, retirando-se lignina e \\ hemicelulose, e visando proporcionar maior rendimento na etapa de hidrólise enzimática para a \\ produção de bioetanol. \\ Biomassa, Biocombustível, Capim elefante guaçú.
}

\section{Introdução}

Recentemente, a produção de etanol a partir de carboidratos provenientes do fracionamento de resíduos de gramíneas vem sendo estudado como uma alternativa para a produção de combustíveis renováveis [1]. As etapas de prétratamento são cruciais para aumentar a eficiência do processo e diferentes métodos podem ter efeitos diversos sobre a estrutura e composição química da biomassa. Assim, neste projeto, testou-se a influência de tratamentos ácidos e básicos sobre o rendimento de hidrólise enzimática no capim elefante.

\section{Resultados e Discussão}

As amostras de folhas de capim elefante guaçú foram tratadas com concentrações de $\mathrm{H}_{2} \mathrm{SO}_{4}$ de $1 \%(\mathrm{v} / \mathrm{v})$, seguido por tratamento com soluções alcalinas de $\mathrm{NaOH}$ de 0,$5 ; 1 ; 2$ e $4 \%(\mathrm{~m} / \mathrm{v})$, colocadas em auto-clave a $121^{\circ} \mathrm{C}$ por $40 \mathrm{~min}$. A etapa ácida removeu $54,7 \%$ da massa seca inicial da amostra. Já na etapa alcalina, a perda de massa seca variou entre 42,0 e 52,6 à medida que as concentrações de base foram aumentando entre 0,5 e $4 \%$. As amostras de folhas de capim elefante foram também caracterizadas quanto à sua morfologia após os tratamentos, utilizando-se microscopia eletrônica de varredura (MEV). O principal efeito do tratamento alcalino sobre as amostras é a separação da estrutura compacta das folhas em fibras individuais, como pode ser observado comparando-se as imagens da Figura 1. À esquerda, a amostra in natura mostra uma morfologia compacta, enquanto a imagem da direita (capim elefante após tratamento com $\mathrm{H}_{2} \mathrm{SO}_{4} 1 \%+\mathrm{NaOH} 0,5 \%$ ), mostra a amostra separada em fibras. A eficiência de hidrólise enzimática nas amostras foi testada em tampão citrato $50 \mathrm{mM}(\mathrm{pH}=5,0)$ após $24 \mathrm{~h}$ de hidrólise com 20 FPU de Accelerase (Genencor) e 30 BGU de $\beta$-glicosidase de Aspergillus niger (SigmaAldrich) a 2,5\% de razão sólido:líquido.
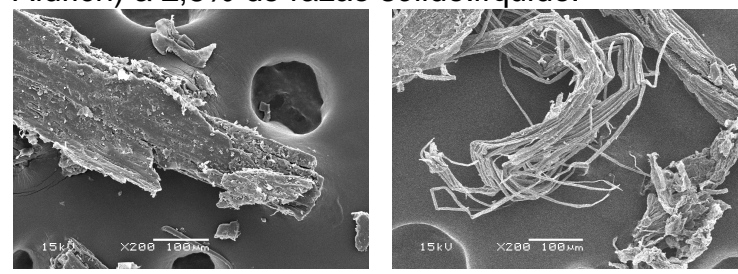

Figura 1. Imagens de MEV em folhas de capim elefante antes (esquerda) e após tratamento com $\mathrm{H}_{2} \mathrm{SO} 41 \%$ e NaOH 0,5\% (direita).

Os resultados mostrados na Tabela 1 de teor de glicose liberada pela ação enzimática $(\mathrm{em} \mathrm{mg} / \mathrm{ml}$ ) nos substratos após os diferentes tratamentos mostram que eles melhoraram significativamente a eficiência de hidrólise nas amostras de capim elefante.

Tabela 1: Glicose liberada após 24h de hidrólise enzimática nas amostra de capim elefante.

\begin{tabular}{|c|c|}
\hline AMOSTRAS & Glicose liberada $(\mathbf{m g} / \mathbf{m l})$ \\
\hline In natura & $3,41 \pm 0,1$ \\
\hline $\mathbf{H}_{2} \mathbf{S O}_{\mathbf{4}} \mathbf{1} \%$ & $11,7 \pm 0,3$ \\
\hline $\mathbf{H}_{\mathbf{2}} \mathbf{S O}_{\mathbf{4}} \mathbf{1} \%+\mathbf{N a O H ~ 0 , 5 \%}$ & $16,4 \pm 0,1$ \\
\hline $\mathbf{H}_{\mathbf{2}} \mathbf{S O}_{\mathbf{4}} \mathbf{1} \%+\mathbf{N a O H ~ 1 \%}$ & $19,1 \pm 0,1$ \\
\hline $\mathbf{H}_{\mathbf{2}} \mathbf{S O}_{\mathbf{4}} \mathbf{1} \%+\mathbf{N a O H ~ 2} \%$ & $18,7 \pm 0,9$ \\
\hline $\mathbf{H}_{\mathbf{2}} \mathbf{S O}_{\mathbf{4}} \mathbf{1} \%+\mathbf{N a O H ~ 4 \%}$ & $21,4,1 \pm 0,2$ \\
\hline
\end{tabular}

\section{Conclusões}

IOs tratamentos aplicados mostraram-se bastante eficientes em aumentar as taxas de açúcares produzidos por hidrólise enzimática nas amostras.

\section{Agradecimentos}

Ao PIBIT/CNPq pela bolsa e pelo Instituto de Zootecnia (IZ) de Nova Odessa, SP pela doação das amostras de capim.

Rezende, C. A.; de Lima, M. A.; Maziero, P.; de Azevedo, E. R.; Garcia, W.; Polikarpov, I. Biotechnology for Biofuels, 2011, 4, 54. 